University of Washington Tacoma

UW Tacoma Digital Commons

$1-1-2008$

\title{
IT Services Project Management: Lessons Learned From a Case Study in Implementation
}

Haluk Demirkan

University of Washington Tacoma, haluk@uw.edu

Jason Nichols

Follow this and additional works at: https://digitalcommons.tacoma.uw.edu/business_pub

\section{Recommended Citation}

Demirkan, Haluk and Nichols, Jason, "IT Services Project Management: Lessons Learned From a Case Study in Implementation" (2008). Business Publications. 63.

https://digitalcommons.tacoma.uw.edu/business_pub/63

This Article is brought to you for free and open access by the Milgard School of Business at UW Tacoma Digital Commons. It has been accepted for inclusion in Business Publications by an authorized administrator of UW Tacoma Digital Commons. 


\title{
IT services project management: lessons learned from a case study in implementation
}

\author{
Haluk Demirkan* \\ W.P. Carey School of Business \\ Arizona State University \\ Tempe, AZ 85287, USA \\ E-mail: Haluk.Demirkan@asu.edu \\ *Corresponding author
}

\section{Jason Nichols}

Department of Management Science and Information Systems

Spears School of Business, Oklahoma State University

Stillwater, Oklahoma 74078-4011, USA

E-mail: jason.nichols@okstate.edu

\begin{abstract}
Project management has gained unprecedented popularity worldwide as companies strive to become more productive, respond quickly to customer needs and stay competitive. However, implementing and managing a formal project-management system is becoming harder as organisations become larger and more complex, the number of the projects undertaken at any given time increases and delivery times become shorter (Levy and Globerson, 2002). This paper includes a review of some of the major multiproject management issues and presents a case study of a successful integrated project-office implementation. Based on the details of the case, a systematic framework that includes the roles and responsibilities, organisational styles and staffing process of an effective project-office programme is developed. Practical guidelines for implementation are presented based on the case and the resulting framework.
\end{abstract}

Keywords: project management and scheduling; issues in project management; single and multiproject management; IT services.

Reference to this paper should be made as follows: Demirkan, H. and Nichols, J. (2008) 'IT services project management: lessons learned from a case study in implementation', Int. J. Project Organisation and Management, Vol. 1, No. 2, pp.204-220.

Biographical notes: Haluk Demirkan is an Assistant Professor of Information Systems in the W.P. Carey School of Business at Arizona State University, USA. His main research interests and expertise are in service-oriented technology and management, and the management of out-tasking relationships. Demirkan has published or has forthcoming works, and has presented his research in a number of academic/industry journals and conferences, such as Information Systems and e-Business Management, Information Systems Frontiers, Communications of the ACM, IEEE Transactions, European Journal of Operations Research, AMCIS, HICSS and DSI. He holds a PhD in Decision and Information Sciences, an ME in Industrial and Systems Engineering both from the University of Florida, USA, and a BS in Mechanical Engineering from Istanbul Technical University, Turkey. 
Jason Nichols is a Visiting Assistant Professor at Oklahoma State University, Stillwater, OK, USA. His research interests include the design of modular systems, services science, decision support, distributed workflow management and complex adaptive systems. He has experience in software development and project management, executive education and training, and information systems consulting.

\section{Introduction}

There are many factors placing pressure on organisations today. Five of the most visible are the existing high project failure rates, the increasing project complexity, the growing Information Technology (IT) outsourcing, the evolving set of regulations such as Sarbanes-Oxley Act and the Health Insurance Portability and Accountability Act (HIPAA), and the need to clearly define project portfolios for creating value and managing risk. These forces highlight the need for effective project management in organisations. Indeed, poor project management has been identified as a key source of project failure in contemporary organisations (Keil, 1995; Lewis, 2007; Whittaker, 1999). The Standish Group, an IT consulting firm, reports that an average \$275 billion is spent on software development projects each year in the US alone (Grenny et al., 2007). More than $70 \%$ of these projects suffer total failure, incur cost and schedule overruns, or deliver fewer functions than promised (Hartman, 2006). Fifty-six percent of projects went over budget and $84 \%$ went past schedule. In total, $23 \%$ of all projects fail, which means the project is cancelled before completion (Johnson, 2000). One reason IS projects fail so often is their relative complexity (Xia and Lee, 2004). Rapidly changing information technology and business environments, pressure to decrease cycle time, and increasing competition and customer demands make any IS development project process difficult to manage. Under this complexity, the IT function is moving towards a portfolio scenario, executing multiple projects concurrently.

IT outsourcing adds a distributed dimension to the complexity of the IT portfolio paradigm. In fact, most of the top US employers have development teams in India and China, and currently the number of IT professionals in India is approximately 140 000-500 000 (Marcus, 2004). Changes in regulations further complicate the matter. For example, two sections in the Sarbanes-Oxley Act highlight the demand for effective project management: Internal Controls (Section 404) and Real Time Disclosure (Section 409). Section 404 requires firms to maintain appropriate controls in place to ensure the accuracy of financial systems. Section 409 requires that all aspects of the business must have streamlined and defined channels of communication to alert management of surprises, both positive and negative. Under this increasing pressure, management of modern firms is shifting to a portfolio approach for projects, requiring demonstrated value creation and increased risk management from the project management function. These needs have given rise to formal mechanisms for demonstrating project value creation, such as the 'earned value management' methodology (Kim et al., 2003; Solomon, 2004). Formal value analysis mechanisms such as these, however, require formal project management methodologies. 
An integrated project management approach is presented below that address the complexity of today's project environment. This approach is then put into context through a case study wherein the details of a Fortune 100 corporation's successful implementation of the project management approach is presented. Following this, practical guidelines are drawn from the details of the framework and the case study in order to support successful future implementations of an integrated project management function.

\section{Integrated project management through the project office}

The concept of the Project Office (PO) is by no means a new idea (e.g., Aubry et al., 2007; 2008; Dai and Wells, 2004; Payne, 1993). This structured approach is well suited to today's chaotic IT business environment. A PO is a key resource in establishing enterprise competency in project analysis, design, management, control and review. It is a shared organisational management structure that coordinates cross-project dependencies. POs formalise management practices and serve as a central organisation responsible for ensuring that standards are adopted and that an environment supporting consistent and repeatable processes is maintained. Along with coordinating cross-project dependencies, a successful PO is a centralised hub for all project data and acts as a communications centre providing status reports to project directors. Within an operating PO, the role of the project manager is to work with the business to make the case for value delivered from the project, develop life cycle cost estimates and determine resources to meet the needs of the project. The PO concept is applicable to any size organisations (e.g., small, medium and large). It is not relevant to size of the organisation. Does not matter, almost all IT organisations have similar project management related issues and challenges.

It has become vital that development efforts surrounding key systems (e.g., Enterprise Resource Planning (ERP), Human Resources (HR), Customer Relationship Management (CRM)) need to be coordinated such that the project management key controls (such as schedule, plan, and estimates) are designed into the system. The PO can serve to coordinate these efforts. As an example, many ERP system implementations have failed not due to the software, but due to poor management processes during the course of project.

Proper project management can help ensure that projects meet expectations and create value. Organisations can achieve a high level of maturity in sophisticated project management practices with an enterprise PO in place. Without high-level oversight, it is far too easy for projects to fall into a 'silo mentality', wherein costs and benefits are assessed at the departmental level or below, versus at the holistic level of the organisation. With an understanding of the needs driving an enterprise PO, the details of a PO framework capable of delivering such capabilities are presented below.

\subsection{Organisational styles for the project office}

A PO is an 'office', either physical or virtual in nature, staffed by project management and control professionals that serves as a repository of information on best practices and methodology for project management. Limits on the scope of a project-office implementation depend on the culture, requirements, and governance realities of the organisation. We adapt from Wilkin and Riddett (2008) the position that three modes 
of IT governance prevail in modern organisations and are, therefore, candidates for the roles of the PO. These modes are 'centralised', where corporate IS assumes project management responsibility, 'decentralised', where authority is deferred to divisional and line management, and 'federal', which is a balance between centralised and decentralised control. Indeed, it is argued that the successful firm will mix structures, processes, and control mechanisms from across all levels of governance (Brown and Magill, 1994; Dixon and John, 1989; LaBelle and Nyce, 1987; LaPlante, 1991; Rockart, 1998; Sambamurthy and Zmud, 1999; von Simson, 1990; Weill and Woodham, 2002).

Therefore, we propose that a PO may exist at any one of the three levels in the organisation - or may exist at all three levels concurrently. Not every PO has the same responsibilities. The levels of a PO are presented below in Table 1, along with a high-level description of three models for PO responsibilities.

Table 1 Overview of the project office structure

Project office levels

Type 1: Project control office. This is an office that typically handles large, complex projects (such as a Y2K project). This may have multiple project managers who are responsible of pieces of the overall programme.

Type 2: Divisional/Business unit project office. A PO may still be required to provide support for individual projects but it is also responsible of integrating the multiple projects.

Type 3: Corporate/Strategic project office. Responsible of coordinating cross-divisional projects.

Project office responsibilities

In the repository model, the PO serves as a source of information on project methodology and standards. It assumes that the enterprise has embraced a cohesive set of tools for project design, management and reporting. This model occurs most often in organisations that empower distributed, business-centric project ownership, or enterprises with weak central governance. Project managers continue to report to and are funded by their respective business areas.

\begin{tabular}{|c|c|}
\hline $\begin{array}{l}\text { In the repository-coach model, } \\
\text { best practices are documented and } \\
\text { shared, and project performance is } \\
\text { actively monitored. Results are used } \\
\text { as an opportunity to raise enterprise } \\
\text { performance and to train inefficient } \\
\text { or new project managers. Mentoring } \\
\text { relationships are established across } \\
\text { business boundaries between } \\
\text { high-performing project managers } \\
\text { and those less skilled. The PO is a } \\
\text { permanent structure, with staff, and } \\
\text { has some supervisory responsibility } \\
\text { for all projects. Also, as noted, the } \\
\text { PO is an internal consultancy } \\
\text { supporting all project managers. }\end{array}$ & $\begin{array}{l}\text { The repository coach } \\
\text { manager model implies } \\
\text { direct management or } \\
\text { oversight, depending on } \\
\text { the scope and duration } \\
\text { of projects within the } \\
\text { enterprise. Sometimes all } \\
\text { project managers of the } \\
\text { organisation are staffed } \\
\text { in the PO. This model } \\
\text { indicates that the PO is } \\
\text { responsible for any type } \\
\text { and size of project, in } \\
\text { regard to every aspect } \\
\text { of project management: } \\
\text { scope, size, risk, impact } \\
\text { and so on. }\end{array}$ \\
\hline
\end{tabular}

In the repository-coach model, 列 actively monitored. Results are use as an opportunity to raise enterprise performance and to train inefficient relationships are established across business boundaries between permanent structure, with staff, and has some supervisory responsibility $\mathrm{PO}$ is an internal consultancy supporting all project managers.

\author{
sitory coach \\ of projects within the \\ enterprise. Sometimes al \\ in the PO. This model \\ indicates that the $\mathrm{PO}$ is \\ responsible for any type \\ and so on.
}

\subsection{Roles and responsibilities of the project office}

Seven key roles for a PO are identifiable from the extant literature described above and field work in PO implementations. Limitations on the scope of the following responsibilities depend on the culture, requirements, and governance realities of the organisation. 


\subsubsection{Project management support}

In most early PO implementations, project managers are not staffed directly from the PO. The main role of the PO is to become a facility to mentor project-management skills in the areas of project integration, scope, time, cost, quality, HR, communications, risk and procurement management. The PO gathers and tracks the information necessary to support the project and ensure success. The PO can also support senior management in establishing and delivering organisational objectives to the individual teams. In essence, the PO manages the fulfilment of stakeholder interests.

\subsubsection{Project management process/methodology}

The PO identifies standardised methodologies for best practices, provides tools and processes for projects, modifies these processes as necessary, and provides a basis for measuring performance. It acts as a communications and training vehicle by developing project skills and concentrating on organisational effectiveness. Because of the centralised focus on project management within the PO, development methodologies are subject to continuous improvement across the lifespan of multiple projects. Some of the standard project deliverables are: work breakdown structures, project plans, status reports, project documentation, dependencies, roles and responsibility assignments, effort estimates, process definition such as issue resolution and task-level guidelines, contingency plans and risk assessment (Dai and Wells, 2004).

\subsubsection{Training}

The PO should act as the centre of focus for project manager and team training, responsible for building and maintaining project management competency areas. The PO also coordinates analysis of and support for the educational needs of project teams.

\subsubsection{Knowledge repository, metrics and analysis}

The PO collects, holds, and analyses old and new project data. The collected metrics data provide information across multiple projects, identifying successes and failures (Aubry et al., 2008). Failures can be highlighted and processes adjusted on the basis of analysis. Successes and special accomplishments can also be identified and recognised publicly by supporting team-based performance reviews.

\subsubsection{Library}

The PO is the central point for any project documentation and archives best business practices.

\subsubsection{Report generation}

With access to the multiple interdependent cross-department projects, the PO is responsible for generating periodic status and issues reports for senior management analysis. 


\subsubsection{Project managers}

In mature PO implementations, the PO maintains a core of qualified project managers who can support any type of short or long term projects (Duncan, 2000). These resources can be loaned out to work on projects.

\subsubsection{Software tools}

A PO centralises the establishment and maintenance of project-related software tools, and supports their use by project teams.

\subsubsection{Portfolio and resource management}

PO's provide ROI analysis for the projects they support. The initial assessment of resources (people, money and time) is critical on several fronts. The PO contributes based on experience and evidence from previous projects by validating business assumptions about a project and its life cycle costs. It also serves senior management by feeding back information that may alter project priorities, based on resource availability or cross-functional project conflicts. Continuously making sure calendars are up-to-date, that naming conventions are followed and that resources are fully optimised without over-commitment are all services provided by the PO. This does not necessarily mean that the PO delegates resources. This responsibility is a function of the PO's position as presented in Table 1 above. However, regardless of resource delegation control, the PO is still responsible for preparing and making available information pertinent to the resource delegation and capacity planning decisions. The formalisation of the PO methodology allows for a finer level of detail concerning the requirements for outsourcing. The literature argues that a greater understanding of the context within which a technology development outsourcing relationship is undertaken provides critical queues regarding how to structure such a partnership (DiRomualdo and Gurbaxani, 1998). PO implementations not only provide such a context, but act as a centralised communication hub for project documentation and asynchronous communication amongst geographically diverse employees and teams.

\subsubsection{Coordination of multiple interdependent projects}

The project plan is a cooperative effort coordinated by the PO, which serves as a competency centre in best practice and as a library for previous projects. The PO is responsible for analysing and assessing the progress of multiple interdependent projects in terms of such projected deliverables as resource utilisation, project portfolio status, cost performance to budget, and multiple project trends (Aubry et al., 2008). Also, the $\mathrm{PO}$ is responsible for the definition and continuous mapping of the master project plan and the organisation's goals with individual teams' project plans.

\subsection{Staffing for the project office}

The size of the staff and skills required for the PO depend on the role that the PO is playing. If it follows a repository model, methodology experts or project librarians may be sufficient. However, if the PO follows a more complex model, it requires project managers in addition to methodology experts. A variety of skills are required to staff a 
PO, depending on its size and the scope of implementation. Due to the coordination role of the PO, it is critical that everybody in the PO have strong interpersonal skills. Typical staff roles and assignments are listed in Table 2. An exemplar organisational chart including the structure of the PO is presented in Figure 1.

Table 2 Typical project office staff roles and assignments

\begin{tabular}{ll}
\hline Staff title & Roles and responsibilities \\
\hline Director/Manager & $\begin{array}{l}\text { Development of project requirements, project integration, resource } \\
\text { prioritisation, project management skills development, project review } \\
\text { and analysis, business interface, human resources (compensation, } \\
\text { review), budget/charging, crisis management } \\
\text { Project specification, analysis, implementation, project } \\
\text { management practices }\end{array}$ \\
Project Managers & $\begin{array}{l}\text { Tracking, reporting and communication of status, data gathering and } \\
\text { analysing, project management tools }\end{array}$ \\
Project Controllers & Back-office support, calendars, scheduling \\
Administrative Support & Project records, repository/maintenance, standards \\
Librarian & Process development and delivery, quality assurance, project \\
Lead Process Engineer & oversight, training \\
Lead Architect & Architectural and infrastructural review \\
\hline
\end{tabular}

Figure 1 Sample organisation chart (see online version for colours)

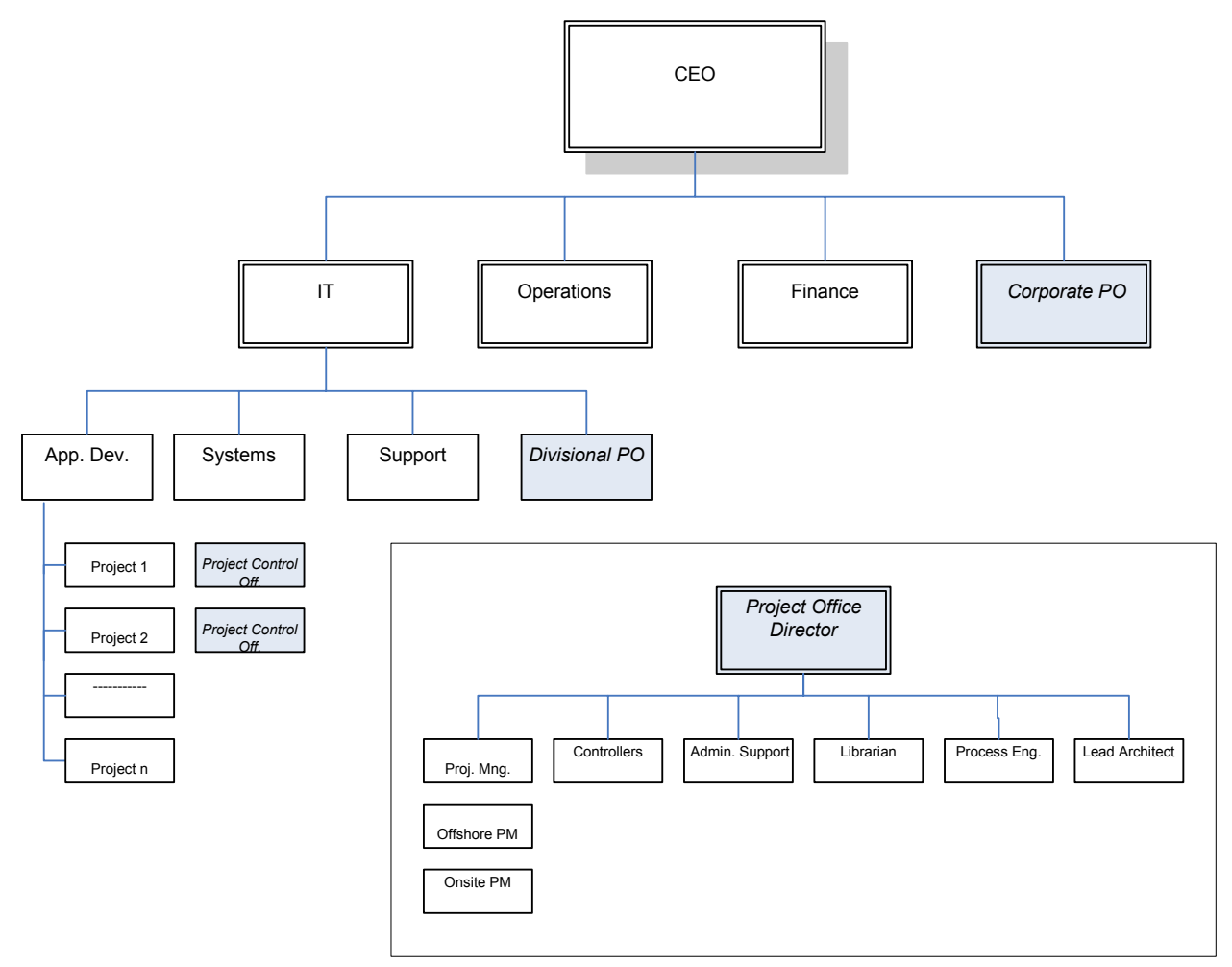




\section{Implementation: a case study}

The company examined is a large, global, financial institution based in the USA. This company, which provides services to more than 20 million customers with a combination of credit and calling card products, was launched in March 1990. The firm is highly successful and enjoys an excellent reputation both within its industry and among its clients. The company's organisational culture can be described as conservative and resistant to change. This conservatism extends to the company's philosophy concerning technology. While the company believes that technology is important to its corporate success, its strong preference is for mature and proven technologies. The company also has a strong belief in the uniqueness of its business model, resulting in a strong bias for the in-house development of systems. If tools or solutions are purchased, they must be flexible enough to adapt to the way the company conducts business and not dictate business processes. Prior to this case, few in the firm had any formal education regarding project management. There were no knowledge or project repositories, no formal project tracking mechanisms, and minimal shared project management methodologies. Each project was dealt with in an ad hoc fashion.

In 1993, the company began a development effort to design and implement a new credit card transaction processing system is to replace an old main frame based system which had very limited functionality. Credit card transaction processing is one of the core business processes for this corporation. The project included more than four years' worth of new development and enhancements to more than 14 client-server and mainframe systems in all business function areas, e.g., marketing, security and fraud, authorisations, accounting, customer service and collections. As early as two years into the initiative, it became clear that the organisation was facing significant overrun issuers. Over time, the scope of the project grew exponentially, and the project was already one year over due. Expenses on the project had more than tripled what was budgeted. From the beginning, this development effort was very much an IT-driven initiative. The business justification for the project was never fully developed, and the potential business uses of each component were not carefully enumerated. This project was initiated by the current Chief Information Officer (CIO) and it was led by a consultant who was reporting to the CIO directly. Approximately 150 out of the 200 team members in the project were consultants or contractors. The prevailing assumption of the development team was that this project would never end. The project had one project manager who was not familiar with the company culture and no architect in place to observe and adhere to the overall organisational architecture. There were development teams in Atlanta (off site developers), India (a mix of employees and contracting firm employees), and Jacksonville (a mix of employees, contractors, and consultants from 12 different firms). The project was in dire straits and the environment surrounding the effort was in chaos.

In 1997, when a new CIO arrived, she decided that she could not pull the plug on this project because of the investments already made and the business need for the new system. Further complicating things, the project had a hard deadline for completion by the end of the second quarter in 1998 in order to free up resources for an upcoming Y2K (year 2000 update) project. In July 1997, the CIO assigned one of the VPs to take leadership of this project. In August 1997, a PO reporting to the project director was established to manage and track the project. Before the PO was created, there were more than 35 project plans for 14 functional areas. Most of these project plans provided 
insufficient information, and there was no master project plan for all the sub-project plans. In addition, some project plans did not have specific resources assigned to their activities, and most of these plans were in different formats. Without complete, detailed project plans, it was very difficult to ensure that the necessary development and implementation activities were performed properly and in a timely fashion. Some critical project activities and deliverables were not documented. Without clearly documented procedures for all critical project activities, any resource changes caused a loss of knowledge, rework activities, and delayed schedules. The critical path for the project was not analysed and communicated to all sub-teams. Documentation of system functionalities was not complete. Without accurate documentation, system functionality could not be adequately tested or delivered, and user training could not be accurately conducted. No backup plan was created for any crisis situation. There were serious communication issues between and within the teams, and some project team members were not aware that their activities were on the preliminary critical path. The project implementation date was delayed many times and was already over budget before the PO was established.

The project director selected a manager for the PO in August 1997 to lay out the office structure for the directing team. The PO initially followed a repository-coach model. First, all the roles and scope of the PO were defined. Staff included the project-office manager, five project managers and controllers, a librarian, a methodology expert and a senior architect. The senior architect was tasked to establish an architecture team from representatives of each functional area to oversee the architectural interdependencies between projects. The methodology expert was responsible for establishing a cross functional team to develop templates for project deliverables. Both the architecture and methodology teams consisted in part of part-time team members who were responsible for spending only $20 \%$ of their time functioning on their respective teams. The main responsibilities of the PO were to integrate project information, evaluate and analyse the overall project, serve as a repository for information on project documentation, and establish project-management methodology and standards. Additionally, the office was charged with improving communication by establishing processes and standards. It also identified cross-functional project conflicts and mentored low-performing project managers.

After identifying roles and responsibilities, and assessing the current condition of the project, the PO identified areas needing similarly formatted project plans and outlined all of them on the master project plan to identify critical paths. A number of processes were developed for clear communication lines, including weekly meetings and status reports, issue resolution, action items, documentation flow between departments and vendors, and so on. All necessary functional documentation was collected and stored under the management of the project librarian.

In order to help recover from a significant scheduling overrun, customer service team members were recruited for early testing and training. During this process, the customer service representatives participated in hands-on training and user acceptance testing. Therefore, the need for post implementation training and testing was significantly reduced. Further, many of the representatives recruited for early testing went on to stay in their new role as IT/IS tester. In this fashion, the project reduced testing and training needs by developing internal resources rather than hiring an external professional trainer. 
During the initial instalment of the project-office programme, American Management Systems (AMS), a major consulting firm, and the PO performed a number of risk assessments to analyse the risk components and the progress of the project, in addition to impact of the PO programme to the organisation. This risk assessment methodology is common amongst research practitioners (Boehm and DeMarco, 1997; Mustafa and Al-Bahar, 1991), and further information regarding its use can be found at http://www.cip.msu.edu/ComFacRAM-HowtoUse.doc. A total of five risk assessment processes in five major categories were evaluated through the AMS (AMS_Consulting, 1997) risk-assessment methodology in a ten-month period. Further, the PO and AMS explored the overall risk average of the set of categories, and within each category the organisational impacts, programme direction, functional plan, technical plan and conversion plan were examined. The results are shown in Table 3. One sub-table and associated value are created for each category, as well as an average of all categories. Several important observations can be made from these results. First, the risk level of this project decreased continuously as PO programme became an established entity. Over time, and through the influence of the PO implementation, the project was eventually stabilised. In the early phase of the PO implementation, April 1997 through August 1997, when the functional and the programme direction/project management risk factors were decreasing, the technical and organisational impacts risk increased. This was likely driven by the utilisation of some project resources for initial analysis and library documentation within the PO itself. After the initial documentation, however, control and management contributions from the PO played a significant role in decreasing all risk factors.

As we see from the risk-assessment data, overall risk decreased as significant progress was made in all areas throughout the process. The PO faced several challenges threatening the implementation strategy and overall performance. At the beginning of the implementation, the PO received serious resistance from the functional team members, most of whom lacked a clear understanding of project-management practices and tools. Pressure from organisational goals and business needs forced the PO to take ownership of all activities and teams without consulting with managers and seeking their help in the transition. Some project leaders anticipated punitive measures and were afraid to provide accurate information on the status of their area. In addition, the senior management for each of these functional areas had different objectives, which resulted in many conflicts and low morale. With the help of very supportive project-director leadership, this PO accomplished salvaging a critical project in a very short time, and transformed the project management structure of the organisation. The transition from little to no formal project management methodology to that of the PO allowed the firm to address individual and team-based personnel issues previously considered the norm.

The case details presented herein highlight a set of problems presented to the modern organisation seeking to streamline their project management operations. These problems are consistent with those highlighted in the literature (Davies and Lawrence, 1977; Hameri and Heikkila, 2002; Williams, 2002; Yeo, 2002), including:

- $\quad$ insufficient understanding of cross-project dependencies

- poor communication between and within the projects

- $\quad$ no formalised procedures and standard processes

- conflicts because of overlapping responsibilities and authorities 
- difficulties in monitoring and controlling resources and projects

- $\quad$ stress from having dual managers

- insufficient risk and impact analysis

- inefficient resource assignment

- insufficient schedule and budget analysis

- significant cost overruns

- scope creep.

Table 3 Risk assessment

\begin{tabular}{|c|c|c|c|c|c|c|}
\hline Key risk categories & Apr- & Aug- & Sep- & Oct- & Dec- & Jan- \\
\hline Overall average of functional plan & 3.33 & 2.00 & 1.67 & 1.67 & 1.67 & 1.33 \\
\hline Business requirements & 3 & 1 & 1 & 1 & 1 & 1 \\
\hline GAPs documented and finalised & 3 & 1 & 1 & 1 & 1 & 1 \\
\hline Functional test planning and test execution & 4 & 4 & 3 & 3 & 3 & 2 \\
\hline Overall average of technical plan & 3.00 & 3.33 & 2.67 & 2.33 & 2.00 & 1.33 \\
\hline Key technical requirements and surround systems & 3 & 4 & 3 & 3 & 2 & 1 \\
\hline Interfaces and transmissions & 2 & 3 & 3 & 2 & 2 & 2 \\
\hline Technical planning and execution & 4 & 3 & 2 & 2 & 2 & 1 \\
\hline Overall average of organisational impacts & 3.67 & 4.00 & 2.00 & 2.00 & 1.33 & 1.33 \\
\hline $\begin{array}{l}\text { Training and methods and procedures planning } \\
\text { and development }\end{array}$ & 3 & 4 & 3 & 3 & 1 & 1 \\
\hline Clear understanding of business impacts & 4 & 4 & 2 & 2 & 2 & 2 \\
\hline $\begin{array}{l}\text { Option set management strategy } \\
\text { and implementation }\end{array}$ & 4 & 4 & 1 & 1 & 1 & 1 \\
\hline $\begin{array}{l}\text { Overall average of programme } \\
\text { direction/project management }\end{array}$ & 3.6 & 3.2 & 1.2 & 1.2 & 1 & 1 \\
\hline Executive and business sponsorship & 3 & 4 & 1 & 1 & 1 & 1 \\
\hline Programme level plan & 3 & 2 & 1 & 1 & 1 & 1 \\
\hline Project management expertise & 4 & 3 & 1 & 1 & 1 & 1 \\
\hline Project management methodology & 4 & 3 & 1 & 1 & 1 & 1 \\
\hline Individual project plans & 4 & 4 & 2 & 2 & 1 & 1 \\
\hline Overall average of conversion plan & 2.75 & 2.75 & 2.25 & 2.5 & 1.5 & 1.25 \\
\hline Conversion data mapping and specifications & 2 & 2 & 1 & 1 & 1 & 1 \\
\hline Conversion and implementation plans & 3 & 3 & 2 & 3 & 2 & 1 \\
\hline Co-existence plan & 3 & 3 & 3 & 3 & 1 & 1 \\
\hline Exit/Re-entry plan & 3 & 3 & 3 & 3 & 2 & 2 \\
\hline Overall average of all categories & 3.27 & 3.06 & 1.96 & 1.94 & 1.5 & 1.25 \\
\hline
\end{tabular}

Notes: Risk levels: 1(minimal risk), 2 (low risk), 3 (medium risk), 4 (high risk).

The recommendations below therefore flow from these issues and the experience gained from facing them as detailed in the case presented above. 


\section{Recommendations for project managers and directors}

The benefits of project-office structures are tremendous, as demonstrated in the case study above. While the implementation of a PO can vary by organisational context (as detailed in the PO framework in Section 2), lessons learned from a PO implementation at a major financial institution can provide some insight into what it takes to succeed with a PO initiative. As such, the recommendations below are derived from that experience as well as characteristics of the PO framework formalisation.

\subsection{Add value}

The best way to get buy-in for the PO method of managing projects is by adding value through obtaining results as quickly as possible. Examples of short-term value-adding initiatives are:

- deployment of a project management methodology

- building an inventory of existing projects

- preparing and communicating status reports

- establishing project success metrics

- establishing support for new projects

- providing templates for recurring project activities.

The key is to keep the implementation simple, focused on value, and structured with a plan. Secure executive sponsorship and effectively communicate the short-term gains of implementation.

\subsection{Assess the current project-development environment}

Identify, address, and eliminate some project and organisational needs for an improved focus at the beginning of the implementation. This assessment should review the technical, cost, schedule, operational and support areas of current projects and the organisation, and specifically identify which business units are using project management and which are not.

\subsection{Verify the existence of established and communicated organisational objectives}

Do so in order to assure that senior managers in the organisation are operating under a common understanding. In this phase, you also need to estimate the appropriate size of the PO for the organisation. If the organisation carries out projects occasionally, there is no need for a very large team in the PO. This organisation will be able to utilise the project-office concept with a small staffing commitment. But with more projects, the need for a large support team becomes more compelling. Use this sizing phase to set expectations and goals concerning the style of PO being established. 


\subsection{Define a strategy}

Using the results from analyses in prior phases, define a strategy to increase performance and productivity of project teams and a strategy for rollout of a cross-functional PO. From a practical perspective, the initial implementation often meets considerable resistance from functional business management, application managers and project managers throughout the organisation because these individuals may view the PO as an intrusion into their domain. Therefore, a successful deployment limits the scope of the implementation to the culture, requirements, and governance realities of the enterprise. Over time, adoption of the PO methodology can act as a catalyst to evolve cultural and governance based resistance.

\subsection{Get executive sponsorship}

When rolling out a project-office structure, it is important to realise that major changes in any organisation must start at the top. Senior management leadership is required to launch the change effort and to provide continuing resources and priorities. Implementations of project management and process improvement require cultural change. The higher the sponsorship in the organisation, the better the chance for success.

\subsection{Assess the staff's skills and knowledge}

One of the biggest mistakes of almost every organisation that implements a PO is in their staffing. In the process of identifying roles, functions, and responsibilities, assess the staff's technical, managerial and interpersonal strengths and weaknesses. The PO should be staffed with experienced project managers and process engineers who have consulting, coaching and mentoring knowledge. As shown in the case study, in the absence of experienced project managers, external resources can be introduced to support training on project management methodology.

\subsection{Ultimately, everyone must be involved}

In this implementation, people are the most important ingredient. It is essential to recognise their desire to do good work. The focus is on repairing the process, not the people. If management insinuates that the people are the problem, process improvement will appear threatening, people will worry about their jobs, and this worry will likely cause resistance to the change. This is why a comprehensive communication plan is another important function of the PO. This plan should include how the office will communicate with all stakeholders - project teams, managers, clients, suppliers and subcontractors. How it will carry over issues and action items, what type of common tools will be used with a common structure, and so on. Note that the PO also acts as a communication tool for employees as well, and feedback must be fed through the PO to management in order for employee buy-in to improve. 


\subsection{Set project standards}

Defining a comprehensive PO implementation and identifying requirements involves defining process boundaries and major groups, identifying process outputs and customers, identifying process inputs and suppliers, identifying sub-processes and flows, validating the process definitions, defining requirements, and creating a precise rollout plan which will be influenced by nine project management knowledge areas: project integration, project scope, project time, project cost, project quality, project human resource, project communications, project risk and project procurement management (Duncan, 2000).

\subsection{Knowledge transfer}

Using the PO as a Knowledge Management Center will help to reinforce the internal strategies and business alignment of the empowering organisation. Realising the potential for failure and/or risk creates a fortified baseline for your projects, and helps to mitigate risk and failure in future projects. The PO is used to map corporate strategies to tactical decisions and operational projects in the organisation. Each operational team should be tied to a tactical decision and corporate strategy.

\subsection{Conduct reinforcement reviews}

Also, establish a continuous project-review system and investigate opportunities for improvement. In addition to issue resolution, teams should have metrics for continuous improvement and efficiency.

\subsection{Be aware of the risks of using a project office}

Risks and rewards go hand-in-hand. The benefits of a PO can be negated if the risks of maintaining a PO are not effectively managed. Most risks do not appear during the creation of the PO, but more so well after implementation. These risks will include:

- Once the organisation begins to recognise the benefits of using a PO, there is a natural tendency to increase headcount in the PO with the false belief that additional benefits will be forthcoming. As more of the organisation becomes knowledgeable in project management, the headcount should decrease.

- Employee burnout is always a risk. Using rotational or part-time assignments can minimise this.

- Excessive paperwork costs millions of dollars to prepare and can waste a lot of time. Project activities work much better when using guidelines, templates and checklists rather that more rigid policies and procedures.

- Given the fact that the PO performs more work laterally than vertically, there can be power struggles for control of the PO. There should be an environment of trust, teamwork, cooperation and effective communication.

- The company must establish some criteria for when the PO should be involved; not all projects should be monitored all the time by a PO. 


\subsection{Measure the success}

A critical question facing many executives is, "How do executives measure the ROI as a result of implementing a PO." It is hard to measure success. To define and establish measures, the PO must review the organisation's objectives and requirements, determine effective measures, and review and validate existing measures against requirements and criteria. Measurement focus is twofold, looking at the performance of the PO and at the performance of the supported projects and larger organisation as well. Some support for measurement of PO impact is presented in Table 4.

Table 4 Measurement dimensions

\begin{tabular}{|c|c|}
\hline Dimensions & Measurements \\
\hline \multirow[t]{4}{*}{ Executive level } & Number of conflicts coming up to the executive levels for resolution \\
\hline & $\begin{array}{l}\text { With a PO and standardisation, the progress reviews are quicker and } \\
\text { more meaningful }\end{array}$ \\
\hline & Decision making will be more efficient by utilising the right amount of data \\
\hline & $\begin{array}{l}\text { The executives can spend less time in meetings and more time dealing with } \\
\text { strategic issues rather than operational issues }\end{array}$ \\
\hline \multirow{4}{*}{$\begin{array}{l}\text { Meeting design } \\
\text { goals }\end{array}$} & Meeting operational specifications \\
\hline & Meeting technical specifications \\
\hline & Meeting time goals \\
\hline & Meeting budget goals \\
\hline \multirow{4}{*}{$\begin{array}{l}\text { Impact on } \\
\text { the customer }\end{array}$} & Fulfilling customer needs \\
\hline & Solving major operational problems \\
\hline & Actually used by the customer \\
\hline & Level of customer satisfaction \\
\hline \multirow{5}{*}{$\begin{array}{l}\text { Benefits to } \\
\text { the organisation }\end{array}$} & Level of commercial success \\
\hline & Generated a large market share \\
\hline & Opened a new market \\
\hline & Opened a new line of products \\
\hline & New technology developed \\
\hline
\end{tabular}

\section{Conclusion}

This paper presents the motivation for a PO to centralise project management initiatives within the firm and coordinate project activities across an increasingly complex organisational landscape. A framework of the key dimensions of PO initiatives in order to address this complexity was presented, followed by a case study implementation in a major financial institution. The case study demonstrated how the tenets of the PO approach to project management can create efficiencies in process, coordinate heterogeneous project teams, centralise and standardise documentation and methodology, and act as a communications channel along the management hierarchy. As demonstrated, however, the case study implementation was not without struggles. As such, the lessons 
learned from that experience coupled with the characteristics of the PO framework were leveraged to present a set of practical guidelines for firms seeking to implement a PO of their own. Considering increasing pressures from regulation, competition, market demands, and a host of other sources detailed in the introduction, the need for a PO seems clear. The findings presented herein seek to ease the transition for firms with minimal support for project management to the formalism of an appropriate PO structure. Even the PO approach is analysed in IT environment; the managerial guidelines are applicable to any project environment.

\section{References}

AMS_Consulting (1997) Risk Assessment Methodology, American Management Systems.

Aubry, M., Hobbs, B. and Thuillier, D. (2007) 'A new framework for understanding organisational project management through the PMO', International Journal of Project Management, May, Vol. 25, No. 4, pp.328-336.

Aubry, M., Hobbs, B. and Thuillier, D. (2008) 'Organisational project management: an historical approach to the study of PMOs', International Journal of Project Management, January, Vol. 26, No. 1, pp.38-43.

Boehm, B. and DeMarco, T. (1997) 'Software risk management', IEEE Software, Vol. 14, No. 3, p.17.

Brown, C. and Magill, S. (1994) 'Alignment of the IS function with the enterprise: toward a model of antecedents', MIS Quarterly, Vol. 18, No. 4, p.371.

Dai, C.X. and Wells, W.G. (2004) 'An exploration of project management office features and their relationship to project performance', International Journal of Project Management, October, Vol. 22, No. 7, pp.523-532.

Davies, S. and Lawrence, P. (1977) Matrix, Massachusetts: Addison-Wesley Publishing Company.

DiRomualdo, A. and Gurbaxani, V. (1998) 'Strategic intent for IT outsourcing', Sloan Management Review, Vol. 39, No. 4, p.67.

Dixon, P. and John, D. (1989) 'Technology issues facing corporate management in the 1990s', MIS Quarterly, Vol. 13, No. 3, p.247.

Duncan, W. (2000) A Guide to the Project Management Body of Knowledge, 3rd ed., Automated Graphic Systems, Project Management Institute.

Grenny, J., Maxfield, D. and Shimberg, A. (2007) 'How project leaders can overcome the crisis of silence', Sloan Management Review, Vol. 48, No. 4, p.46.

Hameri, A. and Heikkila, J. (2002) 'Improving efficiency: time-critical interfacing of project tasks', International Journal of Project Management, Vol. 20, p.143.

Hartman, D. (2006) 'Interview: Jim Johnson of the Standish Group', InfoQueue, http://www .infoq.com/articles/Interview-Johnson-Standish-CHAOS.

Johnson, J. (2000) Chaos in the New Millennium: The Ghost of Christmas Future, The Standish Group, West Yarmouth, Massachusetts.

Keil, M. (1995) 'Pulling the plug: software project management and the problem of project escalation', MIS Quarterly, Vol. 19, No. 4, p.421.

Kim, E., Wells, W. and Duffey, R. (2003) 'A model for effective implementation of earned value management methodology', International Journal of Project Management, Vol. 21, No. 5 , p.375.

LaBelle, A. and Nyce, H. (1987) 'Whither the IT organization?', Sloan Management Review, Vol. 28, p.75.

LaPlante, A. (1991) 'Here come the hybrids', Computerworld, June, p.57. 
Levy, N. and Globerson, S. (2002) 'Improving multi-project management by using queuing theory approach', in R. Apenten, J. Pennypacker and L. Dye (Eds.) Managing Multiple Projects: Planning, Scheduling, and Allocating, CRC Press, p.113.

Lewis, J. (2007) Mastering Project Management: Applying Advanced Concepts to Systems Thinking, McGraw-Hill.

Marcus, A. (2004) 'Insights on outsourcing. What's in it for us? For them? Where are we headed?', Interactions, July-August, p.12.

Mustafa, M. and Al-Bahar, J. (1991) 'Project risk assessment using the analytic hierarchy process', IEEE Transactions on Engineering Management, Vol. 38, No. 1, p.46.

Payne, J. (1993) 'Introducing formal project management into a traditional, functionally structured organization', International Journal of Project Management, November, Vol. 11, No. 4, pp.239-243.

Rockart, J. (1998) 'The line takes the leadership - IS management in a wired society', Sloan Management Review, Summer, p.57.

Sambamurthy, V. and Zmud, R. (1999) 'Arrangement for information technology governance: a theory of multiple contingencies', MIS Quarterly, Vol. 23, No. 2, p.261.

Solomon, P. (2004) 'Integrating systems engineering with earned value management', Defense Acquisition, Technology and Logistics, May-June, p.42.

Von Simson, W. (1990) 'The centrally decentralized IS organization', Harvard Business Review, July-August, p.158.

Weill, P. and Woodham, R. (2002) 'Don't just lead, govern: implementing effective IT governance', CISR Working Paper No. 326.

Whittaker, B. (1999) 'What went wrong? Unsuccessful information technology projects', Information Management \& Computer Security, Vol. 7, No. 1, p.23.

Wilkin, C. and Riddett, J. (2008) 'Issues for IT governance in a large not-for-profit organization: a case study', International MCETECH Conference on e-Technologies, p.193.

Williams, T. (2003) 'Assessing extension of time delays on major projects', International Journal of Project Management, Vol. 21, pp.19-26.

Xia, W. and Lee, G. (2004) 'Grasping the complexity of IS development projects', Communications of the ACM, Vol. 47, No. 5, p.69.

Yeo, K. (2002) 'Critical failure factors in information system projects', International Journal of Project Management, Vol. 20, p.241. 